
\title{
3 Research Square \\ The Role of Pirfenidone in the Treatment of Interstitial Pneumonia With Autoimmune Features
}

\section{Tao Chen}

Tongji University Affiliated Shanghai Pulmonary Hospital

\section{Qiu-Hong Li}

Tongji university affiliated Shanghai Pulmonary Hospital

\section{Yuan Zhang}

Tongji University Affiliated Shanghai Pulmonary Hospital

\section{Cheng-Sheng Yin}

Tongji University Affiliated Shanghai Pulmonary Hospital

\section{Dong Weng}

Tongji University Affiliated Shanghai Pulmonary Hospital

\section{Ying Zhou}

tongji university affiliated Shanghai Pulmonary Hospital

\section{Yang Hu}

Tongji University Affiliated Shanghai Pulmonary Hospital Jing-Yun Shi

Tongji University Affiliated Shanghai Pulmonary Hospital

\section{Ya-Nan Chen}

Tongji University Affiliated Shanghai Pulmonary Hospital

\section{Shuang Ye}

Shanghai Jiao Tong University School of Medicine Affiliated Renji Hospital

\section{Xiao-Dong Wang}

Shanghai Jiaotong University Affiliated Renji hospital

\section{Chun-Yan Wu}

Tongji University Affiliated Shanghai Pulmonary Hospital

\section{Yan Huang}

Tongji University Affiliated Shanghai Pulmonary Hospital

\section{Ai-Hong Zhang}

Tongji University School of Medicine

\section{Huiping Li ( $\square$ liw2013@126.com )}

Department of Respiratory Medicine, Shanghai Pulmonary Hospital, Tongji University, School of Medicine, Shanghai, China https://orcid.org/0000-0002-6998-9828 
Research article

Keywords: Pirfenidone, Interstitial pneumonia with autoimmune features, Mix-effects model

Posted Date: November 2nd, 2020

DOI: https://doi.org/10.21203/rs.3.rs-99703/v1

License: (c) (i) This work is licensed under a Creative Commons Attribution 4.0 International License. Read Full License

Version of Record: A version of this preprint was published at Pathogenesis of rheumatoid arthritis: one year in review 2022 on March 22nd, 2022. See the published version at https://doi.org/10.55563/clinexprheumatol/off5n7. 


\section{Abstract}

Rationale: No approved pharmacotherapies are available for patients with interstitial pneumonia with autoimmune features (IPAF).

Objective: In the present work, we aimed to evaluate the efficacy and safety of pirfenidone for the treatment of IPAF.

Methods: A retrospective cohort study consisting of patients who met diagnostic criteria for IPAF was performed after a multidisciplinary review, and the patients receiving pirfenidone were compared with those in the non-pirfenidone group. The baseline data and diagnostic characteristics of patients were assessed. Pulmonary function and prednisone dose were analyzed by a mix-effects model.

Results: A total of 184 patients, who met the diagnostic criteria of IPAF, were divided into two groups: pirfenidone group ( $n=81)$ and non-pirfenidone group $(n=103)$. Patients in the pirfenidone group had a lower forced vital capacity (FVC\%, $P<0.001)$ and a lower diffusion capacity for carbon monoxide (DLCO\%, $P=0.003)$. The pirfenidone group exhibited a greater increase of $\mathrm{FVC} \%$ at $6(P=0.003), 12$ $(P=0.013)$, and $24(P=0.003)$ months. After adjustment for sex, age, UIP pattern, baseline FVC\% and DLCO\%, patients in the pirfenidone group continued to show a greater improvement in FVC\% ( $\chi 2$ (1) $=4.59, \mathrm{P}=0.032)$. Subgroup analysis identified superior therapeutic effects of pirfenidone in patients with dosage $>600 \mathrm{mg} /$ day $(P=0.010)$ and medication course $>12$ months $(P=0.007)$. Besides, the pirfenidone group had a lower prednisone dose than the non-pirfenidone group after 12 months of treatment $(P=0.002)$. Moreover, 17 patients (19.32\%) experienced side effects after taking pirfenidone, including one case of anaphylactic shock.

Conclusions: Pirfenidone (600-1,800 mg/day) might help improve FVC, with an acceptable safety and tolerability profile in IPAF patients.

\section{Introduction}

As a heterogeneous collection of uncommon disorders, interstitial lung disease (ILD) is characterized by interstitial fibrosis and progressive decline in lung function. A significant proportion of ILD patients demonstrate clinical features suggestive of a connective tissue disease (CTD) but fail to meet established CTD diagnostic criteria. Interstitial pneumonia with autoimmune features (IPAF) is used to label these patients according to a European Respiratory Society/American Thoracic Society research statement ${ }^{[1-2]}$. This new classification system combines clinical, serological, and morphological domains, with an IPAF diagnosis requiring at least two of the three domains. Importantly, IPAF criteria are not diagnostic but standards for classification, which are used to interpret study findings and compare results between studies ${ }^{[3]}$.

The majority of IPAF patients are females, with a mean age of $56.9-67.9$ years ${ }^{[4-9]}$. Moreover, $5-12 \%$ of IPAF patients may develop to definite CTD-ILD ${ }^{[1,5]}$. The most prevalent patterns in the three domains are 
Raynaud's phenomenon and inflammatory arthritis or polyarticular morning stiffness $>60$ min for the clinical domain, non-specific interstitial pneumonia (NSIP) for the morphological domain, and antinuclear antibody (ANA) and rheumatoid factor (RF) for the serological domain. The prognosis of IPAF is superior to idiopathic pulmonary fibrosis (IPF) but worse than CTD-ILD ${ }^{[6-9]}$. Usual interstitial pneumonia (UIP) pattern independently predicts poor survival in IPAF ${ }^{[7-10]}$.

As IPAF patients do not have defined CTD, treatment may be similar to CTD-ILD for some IPAF patients ${ }^{[1]}$. The INBUILD study has shown that nintedanib is beneficial to progressive fibrosing ILD from a variety of CTDs ${ }^{[11]}$. Besides, nintedanib can slow down the annual rate of FVC decline in patients with systemic sclerosis-associated ILD ${ }^{[12]}$. On the other hand, pirfenidone also shows the potential treatment effects for IPAF. A multi-center clinical trial has demonstrated that pirfenidone can prevent the decline of FVC in patients with progressive fibrosing unclassifiable ILD (PF-ILD) ${ }^{[13]}$, including IPAF patients. Li T et al. have reported that pirfenidone can improve the prognosis of patients with amyopathic dermatomyositis ${ }^{[14]}$. Taken together, we postulated that pirfenidone was associated with the improvement of pulmonary function in IPAF patients. To verify such a hypothesis, we explored the efficacy and safety of pirfenidone capsules for the treatment of IPAF, and it was registered in the Chinese Clinical Trial Registry (ChiCTR-IPR17010813).

\section{Patients And Methods}

\section{Screening process of patients}

A total of 1,070 ILD patients diagnosed at Shanghai Pulmonary Hospital (Shanghai, China) from January 2014 to January 2019 were enrolled in this cohort. The screening process is illustrated in Figure 1. Finally, 242 patients met the diagnostic criteria of IPAF ${ }^{22]}$. Among these patients, there were 172 cases with UCTD-ILD, and 70 cases were diagnosed with idiopathic interstitial pneumonia (IIP), including four with biopsy-proven cryptogenic organic pneumonia (COP), eight with IPF, and 58 with unclassifiable IIP. Exclusion criteria were set as follows: (1) patients without follow-up data $(n=30)$; (2) patients with other complications ( $n=15$ including any active infection, heart or hepatic or renal impairment); (3) the duration of pirfenidone treatment was less than 3 months $(n=7)$; and (4) the follow-up interval was more than 40 months $(n=6)$. This study was approved by the Ethics Committee of Shanghai Pulmonary Hospital (Approval No. K17-H1).

\section{Data collection}

Clinical data were collected from patient-visit records, including demographic characteristics, body mass index (BMI), smoking history, RFs and autoantibodies (ANA, anti-CCP, anti-double-stranded DNA, anti-SSA, anti-SSB, anti-RNP, anti-smith, anti-Scl-70, anti-tRNA synthetase), arterial oxygen saturation, and pulmonary function test (PFT). Medication history included glucocorticoids, immunosuppressive agents, and pirfenidone (dosage and duration of therapy). Baseline data were recorded at the time when the patient started pirfenidone or corticoid therapy (allowable range was 0-3 months to permit the inclusion 
of patients). The time table began with the time of baseline for all analyses. PFT was recorded at baseline and after 3 months of pirfenidone treatment, and then it was performed every 6 months as clinically indicated.

\section{Pirfenidone treatment}

Patients with the following situations were recommended to pirfenidone treatment: 1) patients exhibited more than $10 \%$ fibrosis on high-resolution computed tomography (HRCT); 2 ) patients had a more than $5 \%$ absolute decline in percent predicted FVC within the previous 6 months. All the patients started the pirfenidone therapy with a dose of $600 \mathrm{mg} / \mathrm{day}$, and such a dose was increased to $1,800 \mathrm{mg} / \mathrm{day}$ in 6 months unless the patients experienced serious side effects. The final dose (1,800 mg/day) was decided based on the clinical trial of pirfenidone ${ }^{[15]}$. A severe side effect was defined as an event that caused an inability to work or perform daily activity.

\section{Treatment of prednisone and immunosuppressants}

The dose of prednisone was adjusted according to disease severity and body weight. A sufficient dose of prednisone was administered at the beginning, and then it was gradually reduced. Unless the patients experienced an exacerbation, the dose of prednisone would be maintained at a relatively low level. All the immunosuppressants were administered by rheumatologists.

\section{Diagnostic criteria}

The final diagnosis was made by a multidisciplinary discussion (MTD) (three experienced pulmonologists, two rheumatologists, two chest radiologists, and two pathologists). The diagnosis of ILD was made according to the diagnostic criteria described previously ${ }^{[16,17]}$. Diagnosis of IPAF was made based on the evaluation of three diagnostic domains (clinical, serological, and morphological domains) [2]. The morphological domain referred to HRCT or in combination with pathological results when lung biopsies were performed. All patients with CTD-ILD or UCTD-ILD were confirmed by rheumatologists. The diagnostic criteria for CTD in this study followed the recommendations by the American Rheumatism Association and the American College of Rheumatology ${ }^{[18-23]}$. UCTD was defined as patients who showed systemic autoimmune features but did not meet definite classification criteria ${ }^{[1]}$.

\section{Chest HRCT evaluation}

HRCT patterns were blindly reviewed and interpreted by two dedicated chest radiologists. HRCT diagnosis referred to proposed criteria for IPAF by ERS/ATS guidelines ${ }^{[2]}$, including NSIP, organic pneumonia (OP), NSIP in combination with OP, and UIP (Figure S1). NSIP pattern was defined as basal predominant reticular abnormalities with traction bronchiectasis, which was frequently associated with ground-glass attenuation. OP pattern was defined as bilateral patchy areas of consolidation with a subpleural and lower lung zone predominance or peri-bronchovascular distribution. NSIP in combination with OP was defined as basal predominant consolidation, which was associated with features of fibrosis. UIP pattern 
was defined as basal and subpleural predominant honeycombing opacities associated with traction bronchiectasis. No lymphoid interstitial pneumonia (LIP) HRCT pattern was found in this cohort.

\section{Data processing}

Continuous variables were presented as mean (standard deviation) and compared by two-tailed Student's $t$-test. Categorized variables were expressed as frequency (percentage) and compared using the Chisquare test or Wilcoxon rank-sum test. All analyses were performed using GraphPad Prism 6 and SPSS 24 software (IBM, Armonk, NY, USA).

The PFT results were recorded at baseline and follow-up visits. The differences between the follow-up value and baseline value were calculated (change = follow-up value - baseline value), and then the changes in FVC absolute value, FVC\%, and DLCO\% were compared using a mixed-effects model. Fixed effects included gender, age, UIP pattern, baseline FVC\%, and DLCO\%. The mixed-effects model has been proved reliable in other retrospective studies ${ }^{[24-26]}$. The prednisone doses were compared by the same method. These analyses were carried out by R software.

\section{Results}

\section{Baseline characteristics of patients}

Table 1 shows that 184 patients were finally included in the analysis, including 81 (44.0\%) patients in the pirfenidone group, and $103(56.0 \%)$ patients in the non-pirfenidone group. The mean age of the cohort was 59.4 years old, $54.3 \%$ were females, and $53(28.8 \%)$ patients had a history of smoking. There were no differences in gender, smoking history and UIP pattern. However, both FVC\% and DLCO\% were lower in the pirfenidone group compared with the non-pirfenidone group ( $F V C \%, P<0.001 ; D L C O \%, P=0.003$ ). As for the treatment, the baseline data of glucocorticoid and immunosuppressant treatment were not different between the two groups. Generally speaking, 151 (82.1\%) patients received oral glucocorticoid, and 13 (7.1\%) patients received immunosuppressants. The duration of prednisone treatment was $2.25-40$ months, with an average of 28.8 months. The mean duration of pirfenidone treatment was 14.4 months, and the dose of pirfenidone ranged from 600 to $1,800 \mathrm{mg} /$ day, with an average of 1,492 $\mathrm{mg} /$ day.

\section{Diagnostic characteristics of IPAF patients}

Table 2 shows the diagnostic characteristics. Overall, 66 (35.9\%) patients met the diagnostic criteria of IPAF using a combination of serological and morphological domains, $53(28.8 \%)$ patients met the diagnostic criteria of IPAF using clinical and morphological domains, 34 (18.5\%) patients met the diagnostic criteria of IPAF using clinical and serological domains, and 31 (16.8\%) patients met the diagnostic criteria of IPAF using all the three domains.

A breakdown of features into each IPAF domain showed that the most common clinical findings were Raynaud's phenomenon $(49,26.6 \%)$ and inflammatory arthritis or polyarticular morning joint stiffness 
lasting $\geq 60 \mathrm{~min}(45,24.5 \%)$. Moreover, 131 patients had positive serum autoantibody $(71.2 \%)$, and 51 cases had two or more positive antibodies. An ANA $\geq 1: 320$ (or nucleolar or centromere pattern of any titer) was the most common serological finding $(81,44.0 \%)$. Within the morphological domain (150, $81.5 \%$ ), the NSIP pattern by HRCT was found in $62.0 \%$ (114) of patients, while the OP pattern was found in $14.1 \%$ (26) patients. There were no differences in the diagnostic characteristics between the pirfenidone group and the non-pirfenidone group.

\section{Changes in pulmonary function}

The changes in FVC\% (Figure 2A) and DLCO\% (Figure 2B) between the two groups were compared at the time points of $3,6,12,18$, and 24 months. After 12 months of treatment, FVC\% in the pirfenidone group was increased by $10.44 \%$, while such value was decreased by $1.18 \%$ in the non-pirfenidone group $(P=0.013)$. Besides, a greater increase of FVC\% was observed in the pirfenidone group after $6(P=0.003)$ and 24 months $(P=0.003)$. A greater improvement of DLCO\% was also observed in the pirfenidone group after 6 months $(P=0.043)$.

Considering the potential confounders, we estimated the changes of FVC\% (Figure $2 \mathrm{C}$ ) and DLCO\% (Figure 2D) using a mixed-effects model. After adjustment for sex, age, UIP pattern, baseline FVC\%, and DLCO \%, patients in the pirfenidone group continued to show a greater improvement in $\mathrm{FVC} \%[1.49 \%, 95 \%$ $\mathrm{Cl}(0.14 \%, 2.84 \%)]$ compared with the non-pirfenidone group $(X 2(1)=4.59, \mathrm{P}=0.032)$. However, no difference was observed in the change of DLCO\% $(\chi 2(1)=0.49, P=0.48)$. In conclusion, pirfenidone was associated with the improvement of FVC\% in IPAF patients.

\section{Subgroup analysis of the pulmonary function}

To further explore the effect of pirfenidone in different subgroups, subgroup analysis was performed. Table 3 shows the average annual change in FVC absolute value. The volume of FVC (liters) was increased by $0.0390 \mathrm{~L} / \mathrm{year}$ in the pirfenidone group, while such value was decreased by $0.0769 \mathrm{~L} / \mathrm{year}$ in the non-pirfenidone group $(P=0.038)$. The association between pirfenidone use and greater improvement in FVC showed a qualitatively same trend in patients with $\mathrm{FVC}<70 \%(P=0.021)$, with pirfenidone $>600$ $\mathrm{mg} /$ day $(P=0.010)$, and with total medication time $>12$ months $(P=0.007)$. Moreover, pirfenidone also showed superior effects in patients diagnosed by morphological and serological domains $(P=0.033)$. Consequently, pirfenidone treatment had superior effects on FVC improvement when dose $>600 \mathrm{mg} /$ day and treatment time $>12$ months.

\section{IPAF patients can reduce the dose of prednisone after 12 months}

In our cohort, the prednisone dose ranged from 2.5 to $50 \mathrm{mg} /$ day, with an average of $14.4 \mathrm{mg} / \mathrm{day}$. The total dose (Figure 3A) and daily dose (Figure 3B) had no difference between the two groups when assessing the full duration of 40 months. However, when we separated the period into the initial 12 months and the remaining 12-40 months, both the total dose and daily dose of prednisone were significantly lower in the pirfenidone group (total dose, $P=0.012$; daily dose, $P=0.032$ ) during $12-40$ 
months. After adjustment for potential confounders (sex, age, UIP pattern, baseline FVC\%, and baseline DLCO\%) in the mixed-effects model, patients in the pirfenidone group continued to show a reduced dose of prednisone by $6.27 \mathrm{mg}$ per day (Figure $3 \mathrm{C}, \mathrm{D}, \mathrm{E} \times 2$ (1) $=9.8385, P=0.002$, pirfenidone $\mathrm{n}=34$, nonpirfenidone $n=27$ ).

\section{Side effects of pirfenidone}

In the present study, 17 (19.32\%) patients had side effects after taking pirfenidone (Figure 4A) with seven (7.95\%) cases of severe side effects (one case of anaphylactic shock, one case of arthritis, one case of liver injury, one case of photosensitivity, and three cases of skin rash) who stopped the medication. Skin rash $(10.23 \%)$ and liver injury (5.68\%) were the most common side effects, which were similar to those of IPF patients ${ }^{[12]}$. Moreover, 14 (14/17, 82.35\%) patients experienced side effects at the initial dose (600 $\mathrm{mg})$, and three (17.65\%) patients experienced side effects after the dose of pirfenidone was increased (Figure 4B).

\section{Discussion}

Several clinical trials have confirmed the efficacy of pirfenidone in IPF, demonstrating that pirfenidone can delay the decline of FVC and increase the progression-free survival rates ${ }^{[15,27-28]}$. However, no study has explored the effects of pirfenidone in IPAF patients. Our observational study identified that the use of pirfenidone was associated with the improvement of $\mathrm{FVC}$ and the reduction of prednisone dose. The strengths of the study included the longitudinal data of PFT and prednisone dosage throughout 40 months as well as subgroup analyses of lung function.

The pathological features of IPAF are autoimmune inflammatory exudation and interstitial fibrosis. Therefore, the treatment for IPAF would cover both of the two sides. Wiertz et al. ${ }^{[29]}$ have reported that IPAF patients may benefit from cyclophosphamide treatment. Besides, McCoy et al. ${ }^{[30]}$ have shown that mycophenolate therapy can attenuate disease progression in IPAF patients. Nevertheless, all these published studies are designed to explore the effect of immunosuppressive therapy. No studies have yet explored the effect of anti-fibrosis treatment in IPAF patients. In the present study, we, for the first time, reported that the anti-fibrosis treatment of pirfenidone could improve the pulmonary function of IPAF patients.

The average dosage of pirfenidone was 1,492 mg/day, suggesting that the dosage of pirfenidone for IPAF was not necessarily as high as that for IPF. Reasons might be as follows: 1) IPAF patients are relatively younger than IPF patients, as the mean age is $57-68$ for IPAF ${ }^{[4-9]}$ and $68-79$ for $\operatorname{IPF}^{[17,27-28]}$ at diagnosis; 2) IPAF patients have more inflammatory exudative lesions on chest CT scans (i.g. NSIP and $\mathrm{OP})$; 3) pirfenidone is mostly prescribed in combination with glucocorticoids; and 4) effective dose for East-Asian patients may be lower than Caucasian. In a phase-III clinical trial in Japan ${ }^{[28]}$, the effective dose of pirfenidone is $1,800 \mathrm{mg} /$ day or $1,200 \mathrm{mg} /$ day for IPF patients, which is lower than that in clinical trials (CAPACITY and ASCEND) in Caucasians $\left(2,400 \mathrm{mg} /\right.$ day) ${ }^{[27,28]}$. Besides, we began with a low dose 
(600 mg/day) for the following considerations. 1) We observed that a low dose could achieve a certain effect on IPAF patients. 2) Low dose could help prevent side effects. 3) There is a heavier financial burden for some patients in China if they take a high dose of pirfenidone. The duration of pirfenidone treatment was similar between our study and the IPF clinical trials ${ }^{[15,27,28]}$. Both indicated that the change of FVC was noted when the medication course was longer than 12 months.

The overall incidence of side effects was lower (19.32\%) in the present study compared with other IPF clinical trials ${ }^{[27,28]}$. Only $10.23 \%$ of the patients had skin rash in our study, while such proportion is 28.1 -

$32 \%$ in other IPF clinical trials ${ }^{[27,28]}$, which could be explained by the lower dose of pirfenidone (average $1,492 \mathrm{mg} /$ day) in our study. The side effects of pirfenidone were dose-related in this study. Three (3.4\%) patients experienced skin rash and liver damage when the pirfenidone dose was increased. These results further demonstrated the benefits of lower-dose pirfenidone for IPAF patients.

Corticosteroids are widely used in IPAF patients. In the present study, the steroid dose was significantly reduced when pirfenidone was used for initial steroid-sparing therapy. Specifically, the dose of prednisone was reduced by $6.27 \mathrm{mg}$ per day in the pirfenidone group after 12 months of pirfenidone treatment. Consistent with this, J. A. Huapaya et al. have reported the use of immunosuppressants (azathioprine and mycophenolate) in 110 patients with myositis-related ILD (M-ILD) is associated with the reduction of prednisone dose ${ }^{[31]}$. The reduction of prednisone dose prevents the side effects of corticoids, therefore improving the medication compliance and treatment outcomes in IPAF patients.

Our study has several limitations. First, the study is limited to reporting associations, but unable to identify causal relationships due to the retrospective, single-center, and observational nature. Second, patients were not randomized to pirfenidone treatment. Therefore, pirfenidone exposure might cause an indication bias. Patients receiving pirfenidone were more likely to have a progressive fibrosing ILD. However, the subgroup analysis identified the same effect of pirfenidone in patients with FVC $\%<70 \%$. Besides, limited follow-up of subjects over time might lead to misleading estimates of beneficial drug effects. Nevertheless, the follow-up bias could be weakened by adding the time interval as a random effect into the mixed-effects model. Last, although the analysis was adjusted by the mixed-effects model, system differences in the cohorts could not be ignored. Therefore, our current findings need to be confirmed by prospective studies. However, multi-center clinical trials cannot be accomplished in a short time. Therefore, in the meantime, our study might help provide suggestions for therapy in IPAF patients.

\section{Conclusions}

Collectively, our findings indicated that low-dose pirfenidone (1,492 mg/day) might help improve FVC with an acceptable safety and tolerability profile in IPAF patients.

\section{Abbreviations}


$\mathrm{BMI}=$ body mass index; $\mathrm{COP}=$ cryptogenic organic pneumonia; $\mathrm{CTD}-\mathrm{ILD}=$ Connective tissue diseaseassociated ILD; DLCO= diffusion capacity of the lung for carbon monoxide; FVC= Forced vital capacity; HRCT=high-resolution computed tomography; IIP= idiopathic interstitial pneumonia; ILD= Interstitial lung disease; IPAF=Interstitial pneumonia with autoimmune features; IPF= idiopathic pulmonary fibrosis; $M T D=$ multidisciplinary discussion; NSIP= Non-specific interstitial pneumonia;

\section{Declarations}

\section{Ethics approval and consent to participate}

This study was approved by the Ethics Committee of Shanghai Pulmonary Hospital (Approval No. K17H1). Informed consent was obtained from all patients before.

enrollment in this study.

\section{Consent for publication}

Not applicable.

\section{Availability of data and materials}

All data generated or analyzed during this study are included in this article.

\section{Competing interests}

The authors declare that they have no competing interests.

\section{Funding}

This study was financially supported by the National Natural Science Foundation of China (Grant Nos. $81730002,81670055,81670056,91442103,81500052$, and 81570057), Ministry of Science and Technology of the People's Republic of China (Grant Nos. 2016YFC1100200 and 2016YFC1100204), National Science Foundation of Shanghai (18ZR143400) and Shanghai Family Planning Commission Health Industry Clinical Research Project (Grant No. 20184Y0084).

\section{Authors' Contributions}

HPL, TC, QHL, and YZ participated in the conception, hypothesis, and design of the study. TC, CSY, and QHL collected data. TC, and YZ carried out the statistical analyses. All authors contributed to interpretation of the data. TC and HPL drafted the manuscript, and all authors made critical revisions. All authors studied and approved the final version of the manuscript.

\section{Acknowledgements}

Not applicable. 


\section{References}

1. Yang Hu, Liu-Sheng Wang, Yaru Wei,Shan-Shan Du, Yu-Kui Du, Xian He, Nan Li, Ying Zhou,Qiu-Hong Li, Yi-Liang Su, Fen Zhang, Li Shen, Dong Weng, Kevin K. Brown and Hui-Ping Li. Clinical characteristics of connective tissue disease-associated interstitial lung disease in 1044 Chinese patients. Chest, 2016, 149(1):201-208

2. Fischer A, Antoniou KM, Brown KK, Cadranel J, Corte TJ, du Bois RM, Lee JS, Leslie KO, Lynch DA, Matteson EL, Mosca M, Noth I, Richeldi L, Strek ME, Swigris JJ, Wells AU, West SG, Collard HR, Cottin V, CTD-ILD EATFoUFo. An official European Respiratory Society/American Thoracic Society research statement: interstitial pneumonia with autoimmune features. The European respiratory journal 2015: 46(4): 976-987.

3. Aggarwal R, Ringold S, Khanna D, Neogi T, Johnson SR, Miller A, Brunner HI, Ogawa R, Felson D, Ogdie A, Aletaha D, Feldman BM. Distinctions between diagnostic and classification criteria? Arthritis care \& research 2015: 67(7): 891-897.

4. Dai J, Wang L, Yan X, Li H, Zhou K, He J, Meng F, Xu S, Liang G, Cai H. Clinical features, risk factors, and outcomes of patients with interstitial pneumonia with autoimmune features: a population-based study. Clinical rheumatology 2018: 37(8): 2125-2132.

5. Ito Y, Arita M, Kumagai S, Takei R, Noyama M, Tokioka F, Nishimura K, Koyama T, Notohara K, Ishida T. Serological and morphological prognostic factors in patients with interstitial pneumonia with autoimmune features. BMC pulmonary medicine 2017: 17(1): 111.

6. Kelly BT, Moua T. Overlap of interstitial pneumonia with autoimmune features with undifferentiated connective tissue disease and contribution of UIP to mortality. Respirology 2018: 23(6): 600-605.

7. Chartrand S, Swigris JJ, Stanchev L, Lee JS, Brown KK, Fischer A. Clinical features and natural history of interstitial pneumonia with autoimmune features: A single center experience. Respiratory medicine 2016: 119: 150-154.

8. Yoshimura K, Kono M, Enomoto $Y$, Nishimoto $K$, Oyama $Y$, Yasui $H$, Hozumi H, Karayama M, Suzuki $Y$, Furuhashi K, Enomoto N, Fujisawa T, Nakamura Y, Inui N, Sumikawa H, Johkoh T, Colby TV, Sugimura $\mathrm{H}$, Suda T. Distinctive characteristics and prognostic significance of interstitial pneumonia with autoimmune features in patients with chronic fibrosing interstitial pneumonia. Respiratory medicine 2018: 137: 167-175.

9. Oldham JM, Adegunsoye A, Valenzi E, Lee C, Witt L, Chen L, Husain AN, Montner S, Chung JH, Cottin V, Fischer A, Noth I, Vij R, Strek ME. Characterisation of patients with interstitial pneumonia with autoimmune features. The European respiratory journal 2016: 47(6): 1767-1775.

10. Chung JH, Montner SM, Adegunsoye A, Lee C, Oldham JM, Husain AN, MacMahon H, Noth I, Vij R, Strek ME. CT Findings, Radiologic-Pathologic Correlation, and Imaging Predictors of Survival for Patients With Interstitial Pneumonia With Autoimmune Features. AJR American journal of roentgenology 2017: 208(6): 1229-1236. 
11. Flaherty KR, Wells AU, Cottin V, Devaraj A, Walsh SLF, Inoue Y, Richeldi L, Kolb M, Tetzlaff K, Stowasser S, Coeck C, Clerisme-Beaty E, Rosenstock B, Quaresma M, Haeufel T, Goeldner RG, Schlenker-Herceg R, Brown KK, Investigators IT. Nintedanib in Progressive Fibrosing Interstitial Lung Diseases. The New England journal of medicine 2019: 381(18): 1718-1727.

12. Distler O, Highland KB, Gahlemann M, Azuma A, Fischer A, Mayes MD, Raghu G, Sauter W, Girard M, Alves M, Clerisme-Beaty E, Stowasser S, Tetzlaff K, Kuwana M, Maher TM, Investigators ST. Nintedanib for Systemic Sclerosis-Associated Interstitial Lung Disease. The New England journal of medicine 2019: 380(26): 2518-2528.

13. Maher TM, Corte TJ, Fischer A, Kreuter M, Lederer DJ, Molina-Molina M, Axmann J, Kirchgaessler KU, Samara K, Gilberg F, Cottin V. Pirfenidone in patients with unclassifiable progressive fibrosing interstitial lung disease: a double-blind, randomised, placebo-controlled, phase 2 trial. The Lancet Respiratory medicine 2020: 8(2): 147-157.

14. Li T, Guo L, Chen Z, Gu L, Sun F, Tan X, Chen S, Wang X, Ye S. Pirfenidone in patients with rapidly progressive interstitial lung disease associated with clinically amyopathic dermatomyositis. Scientific reports 2016: 6: 33226 .

15. Taniguchi H, Ebina M, Kondoh Y, Ogura T, Azuma A, Suga M, Taguchi Y, Takahashi H, Nakata K, Sato A, Takeuchi M, Raghu G, Kudoh S, Nukiwa T, Pirfenidone Clinical Study Group in J. Pirfenidone in idiopathic pulmonary fibrosis. The European respiratory journal 2010: 35(4): 821-829.

16. Travis WD, Costabel U, Hansell DM, King TE, Jr., Lynch DA, Nicholson AG, Ryerson CJ, Ryu JH, Selman M, Wells AU, Behr J, Bouros D, Brown KK, Colby TV, Collard HR, Cordeiro CR, Cottin V, Crestani B, Drent M, Dudden RF, Egan J, Flaherty K, Hogaboam C, Inoue Y, Johkoh T, Kim DS, Kitaichi M, Loyd J, Martinez FJ, Myers J, Protzko S, Raghu G, Richeldi L, Sverzellati N, Swigris J, Valeyre D, Pneumonias AEColl. An official American Thoracic Society/European Respiratory Society statement: Update of the international multidisciplinary classification of the idiopathic interstitial pneumonias. American journal of respiratory and critical care medicine 2013: 188(6): 733-748.

17. Raghu G, Collard HR, Egan JJ, Martinez FJ, Behr J, Brown KK, Colby TV, Cordier JF, Flaherty KR, Lasky JA, Lynch DA, Ryu JH, Swigris JJ, Wells AU, Ancochea J, Bouros D, Carvalho C, Costabel U, Ebina M, Hansell DM, Johkoh T, Kim DS, King TE, Jr., Kondoh Y, Myers J, Muller NL, Nicholson AG, Richeldi L, Selman M, Dudden RF, Griss BS, Protzko SL, Schunemann HJ, Fibrosis AEJACoIP. An official ATS/ERS/JRS/ALAT statement: idiopathic pulmonary fibrosis: evidence-based guidelines for diagnosis and management. American journal of respiratory and critical care medicine 2011: 183(6): 788-824.

18. Sharp GC, Irvin WS, Tan EM, Gould RG, Holman HR. Mixed connective tissue disease-an apparently distinct rheumatic disease syndrome associated with a specific antibody to an extractable nuclear antigen (ENA). The American journal of medicine 1972: 52(2): 148-159.

19. Bohan A, Peter JB. Polymyositis and dermatomyositis (first of two parts). The New England journal of medicine 1975: 292(7): 344-347. 
20. Preliminary criteria for the classification of systemic sclerosis (scleroderma). Subcommittee for scleroderma criteria of the American Rheumatism Association Diagnostic and Therapeutic Criteria Committee. Arthritis and rheumatism 1980: 23(5): 581-590.

21. Tan EM, Cohen AS, Fries JF, Masi AT, McShane DJ, Rothfield NF, Schaller JG, Talal N, Winchester RJ. The 1982 revised criteria for the classification of systemic lupus erythematosus. Arthritis and rheumatism 1982: 25(11): 1271-1277.

22. Arnett FC, Edworthy SM, Bloch DA, McShane DJ, Fries JF, Cooper NS, Healey LA, Kaplan SR, Liang $\mathrm{MH}$, Luthra HS, et al. The American Rheumatism Association 1987 revised criteria for the classification of rheumatoid arthritis. Arthritis and rheumatism 1988: 31(3): 315-324.

23. Vitali C, Bombardieri S, Moutsopoulos HM, Coll J, Gerli R, Hatron PY, Kater L, Konttinen YT, Manthorpe R, Meyer O, Mosca M, Ostuni P, Pellerito RA, Pennec Y, Porter SR, Richards A, Sauvezie B, Schiodt M, Sciuto M, Shoenfeld Y, Skopouli FN, Smolen JS, Soromenho F, Tishler M, Wattiaux MJ, et al. Assessment of the European classification criteria for Sjogren's syndrome in a series of clinically defined cases: results of a prospective multicentre study. The European Study Group on Diagnostic Criteria for Sjogren's Syndrome. Annals of the rheumatic diseases 1996: 55(2): 116-121

24. 24.Kreuter M, Wuyts W, Renzoni E, Koschel D, Maher TM, Kolb M, Weycker D, Spagnolo P, Kirchgaessler KU, Herth FJ, Costabel U. Antacid therapy and disease outcomes in idiopathic pulmonary fibrosis: a pooled analysis. The Lancet Respiratory medicine 2016: 4(5): 381-389.

25. Strand MJ, Sprunger D, Cosgrove GP, Fernandez-Perez ER, Frankel SK, Huie TJ, Olson AL, Solomon J, Brown KK, Swigris JJ. Pulmonary function and survival in idiopathic vs secondary usual interstitial pneumonia. Chest 2014: 146(3): 775-785.

26. Mao B, Yang JW, Lu HW, Xu JF. Asthma and bronchiectasis exacerbation. The European respiratory journal 2016: 47(6): 1680-1686.

27. King TE, Jr., Bradford WZ, Castro-Bernardini S, Fagan EA, Glaspole I, Glassberg MK, Gorina E, Hopkins PM, Kardatzke D, Lancaster L, Lederer DJ, Nathan SD, Pereira CA, Sahn SA, Sussman R, Swigris JJ, Noble PW, Group AS. A phase 3 trial of pirfenidone in patients with idiopathic pulmonary fibrosis. The New England journal of medicine 2014: 370(22): 2083-2092.

28. Noble PW, Albera C, Bradford WZ, Costabel U, Glassberg MK, Kardatzke D, King TE, Jr., Lancaster L, Sahn SA, Szwarcberg J, Valeyre D, du Bois RM, Group CS. Pirfenidone in patients with idiopathic pulmonary fibrosis (CAPACITY): two randomised trials. Lancet 2011: 377(9779): 1760-1769.

29. Wiertz IA, van Moorsel CHM, Vorselaars ADM, Quanjel MJR, Grutters JC. Cyclophosphamide in steroid refractory unclassifiable idiopathic interstitial pneumonia and interstitial pneumonia with autoimmune features (IPAF). The European respiratory journal 2018: 51(4).

30. McCoy SS, Mukadam Z, Meyer KC, Kanne JP, Meyer CA, Martin MD, Sampene E, Aesif SW, Rice LN, Bartels CM. Mycophenolate therapy in interstitial pneumonia with autoimmune features: a cohort study. Therapeutics and clinical risk management 2018: 14: 2171-2181.

31. Huapaya JA, Silhan L, Pinal-Fernandez I, Casal-Dominguez M, Johnson C, Albayda J, Paik JJ, Sanyal A, Mammen AL, Christopher-Stine L, Danoff SK.Long-Term Treatment With Azathioprine and 
Mycophenolate Mofetil for Myositis-Related Interstitial Lung Disease. Chest 2019: 156(5): 896-906

\section{Tables}

Table 1. Baseline characteristics of patients.

\begin{tabular}{|c|c|c|c|c|}
\hline Characteristics & Total & Pirfenidone & $\begin{array}{l}\text { Non- } \\
\text { pirfenidone }\end{array}$ & P-value \\
\hline & $N=184$ & $N=81$ & $N=103$ & \\
\hline Age (year) & $59.4 \pm 9.5$ & $58.0 \pm 10.3$ & $60.5 \pm 8.7$ & 0.077 \\
\hline Female, n (\%) & $100(54.3)$ & $49(60.5)$ & $51(49.5)$ & 0.176 \\
\hline BMI & $24.8 \pm 2.9$ & $25.0 \pm 3.1$ & $24.7 \pm 2.8$ & 0.521 \\
\hline \multicolumn{5}{|l|}{ Smoking status } \\
\hline Ever, n (\%) & $53(28.8)$ & $20(24.7)$ & $33(32.0)$ & 0.326 \\
\hline Current, n (\%) & $30(16.3)$ & $9(11.1)$ & $21(20.4)$ & 0.109 \\
\hline \multicolumn{5}{|l|}{ Observation periods(months) } \\
\hline & $15.0 \pm 11.4$ & $14.6 \pm 10.3$ & $15.4 \pm 12.4$ & 0.649 \\
\hline \multicolumn{5}{|l|}{ Pulmonary function } \\
\hline FVC (Liters) & $2.00 \pm 0.67$ & $1.86 \pm 0.67$ & $2.10 \pm 0.65$ & $0.013^{*}$ \\
\hline FVC, \%predicted & $64.7 \pm 16.6$ & $59.7 \pm 15.8$ & $68.6 \pm 16.3$ & $<0.001^{*}$ \\
\hline DLCO, \%predicted & $59.3 \pm 18.7$ & $54.3 \pm 17.9$ & $63.0 \pm 18.6$ & $0.003^{*}$ \\
\hline $\mathrm{PaO}_{2}$ & $83.0 \pm 17.9$ & $81.4 \pm 1.9$ & $84.3 \pm 1.7$ & 0.266 \\
\hline $\mathrm{SaO}_{2} \%$ & $95.5 \pm 4.0$ & $95.5 \pm 2.5$ & $95.6 \pm 4.8$ & 0.881 \\
\hline UIP pattern on CT & $57(31.0)$ & $21(25.9)$ & $36(33.3)$ & 0.337 \\
\hline \multicolumn{5}{|l|}{ Treatment } \\
\hline Corticosteroids n (\%) & $151(82.1)$ & $69(85.2)$ & $82(79.6)$ & 0.342 \\
\hline Maximal dose of prednisone(mg/day) & $31.9 \pm 1.3$ & $33.2 \pm 1.2$ & $30.9 \pm 1.4$ & 0.198 \\
\hline Time for prednisone (months) & $28.8 \pm 5.6$ & $29.7 \pm 4.3$ & $28.1 \pm 6.2$ & 0.438 \\
\hline Immunosuppressant n (\%) & $13(7.1)$ & $7(8.6)$ & $6(5.8)$ & 0.459 \\
\hline
\end{tabular}

Abbreviations: BMI, body mass index; FVC, forced vital capacity; DLCO, carbon monoxide diffusing capacity. * $P<0.05$ 
Table 2. Proportion of each domain of IPAF 


\begin{tabular}{|c|c|c|c|c|}
\hline & $\begin{array}{l}\text { Total } \\
\mathrm{n}(\%)\end{array}$ & $\begin{array}{l}\text { Pirfenidone } \\
\mathrm{n}(\%)\end{array}$ & $\begin{array}{l}\text { Non- } \\
\text { pirfenidone } \\
\mathrm{n}(\%)\end{array}$ & $\begin{array}{l}P \\
\text { value }\end{array}$ \\
\hline Subjects & 184 & 81 & 103 & \\
\hline Clinical and serological & $34(18.5)$ & 11(13.6) & $23(22.3)$ & 0.180 \\
\hline Clinical and morphological & $53(28.8)$ & $25(30.9)$ & $28(27.2)$ & 0.625 \\
\hline Serological and morphological & $66(35.9)$ & $31(38.3)$ & $35(34.0)$ & 0.547 \\
\hline All three domains & $31(16.8)$ & $14(17.3)$ & $17(16.5)$ & 1.000 \\
\hline Clinical domain & $118(64.1)$ & $50(61.7)$ & $68(66.0)$ & 0.643 \\
\hline Mechanical hands & $14(7.6)$ & $5(6.0)$ & $9(8.7)$ & 0.472 \\
\hline Distal digital tip ulceration & $3(1.6)$ & $1(1.2)$ & $2(1.9)$ & 0.684 \\
\hline $\begin{array}{l}\text { Inflammatory arthritis or polyarticular morning } \\
\text { joint stiffness } \geq 60 \mathrm{~min}\end{array}$ & $45(24.5)$ & $20(24.7)$ & $25(24.3)$ & 0.948 \\
\hline Palmer telangiectasia & $8(4.3)$ & $5(6.0)$ & $3(2.9)$ & 0.307 \\
\hline Raynaund's phenomenon & $49(26.6)$ & $23(28.4)$ & $26(25.2)$ & 0.737 \\
\hline Unexplained digital edema & $7(3.8)$ & $3(3.7)$ & $4(3.9)$ & 0.950 \\
\hline Gottron's sign & $2(1.1)$ & $1(1.2)$ & $1(1.0)$ & 0.864 \\
\hline Serological domain $※$ & $131(71.2)$ & $56(69.1)$ & $75(72.8)$ & 0.625 \\
\hline प & $80(43.5)$ & $31(38.3)$ & $49(47.6)$ & \multirow{4}{*}{0.240} \\
\hline प & $26(14.1)$ & $12(14.8)$ & $14(13.6)$ & \\
\hline प & $18(9.8)$ & $10(12.3)$ & $8(7.8)$ & \\
\hline प & $7(3.8)$ & $3(3.7)$ & $4(3.9)$ & \\
\hline Antinuclear antibody \# & $81(44.0)$ & $38(46.9)$ & $43(41.7)$ & 0.550 \\
\hline Rheumatoid factor $\geq 2$ upper limit normal & $49(26.6)$ & $17(21.0)$ & $32(31.1)$ & 0.125 \\
\hline Anti-cyclic citrullinated peptide (CCP) & $1(0.5)$ & $1(1.2)$ & $0(0)$ & 0.258 \\
\hline Anti-double stranded DNA & $6(3.3)$ & $2(2.5)$ & $4(3.9)$ & 0.592 \\
\hline Anti-SSA & $27(14.7)$ & $14(17.3)$ & $13(12.6)$ & 0.375 \\
\hline Anti-SSB & $15(8.2)$ & $8(9.9)$ & $7(6.8)$ & 0.448 \\
\hline Anti-ribonucleoprotein (RNP) & $3(1.6)$ & $2(2.5)$ & $1(1.0)$ & 0.426 \\
\hline Anti-smith & $11(6.0)$ & $5(6.2)$ & $6(5.8)$ & 0.921 \\
\hline
\end{tabular}




\begin{tabular}{|lllll|}
\hline Anti-topoisomerase $(\mathrm{Scl}-70)$ & $4(2.2)$ & $3(3.7)$ & $1(1.0)$ & 0.207 \\
\hline Anti-tRNA synthetase & $17(9.2)$ & $7(8.6)$ & $10(9.7)$ & 0.804 \\
\hline Morphological domain & $150(81.5)$ & $70(86.4)$ & $80(77.7)$ & 0.180 \\
\hline NSIP & $114(62.0)$ & $51(63.0)$ & $63(61.2)$ & 0.879 \\
\hline OP & $26(14.1)$ & $13(16.0)$ & $13(12.6)$ & 0.508 \\
\hline NSIP+OP & $10(5.4)$ & $6(7.4)$ & $4(3.9)$ & 0.295 \\
\hline
\end{tabular}

Morphological domain is referred to the HRCT. Abbreviations: NSIP, non-specific interstitial pneumonia;

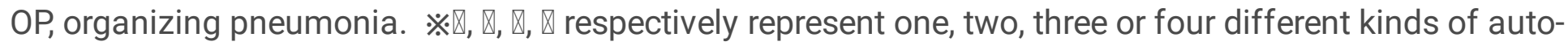
antibodies are positive with the patients. \#ANA $\geqslant 1: 320$ titer, diffuse, speckled, homogeneous patterns or a. ANA nucleolar pattern (any titer) or b. ANA centromere pattern (any titer). ${ }^{*} P<0.05$

\section{Table 3. Analysis of change in Forced Vital Capacity(liters) Outcome\#}




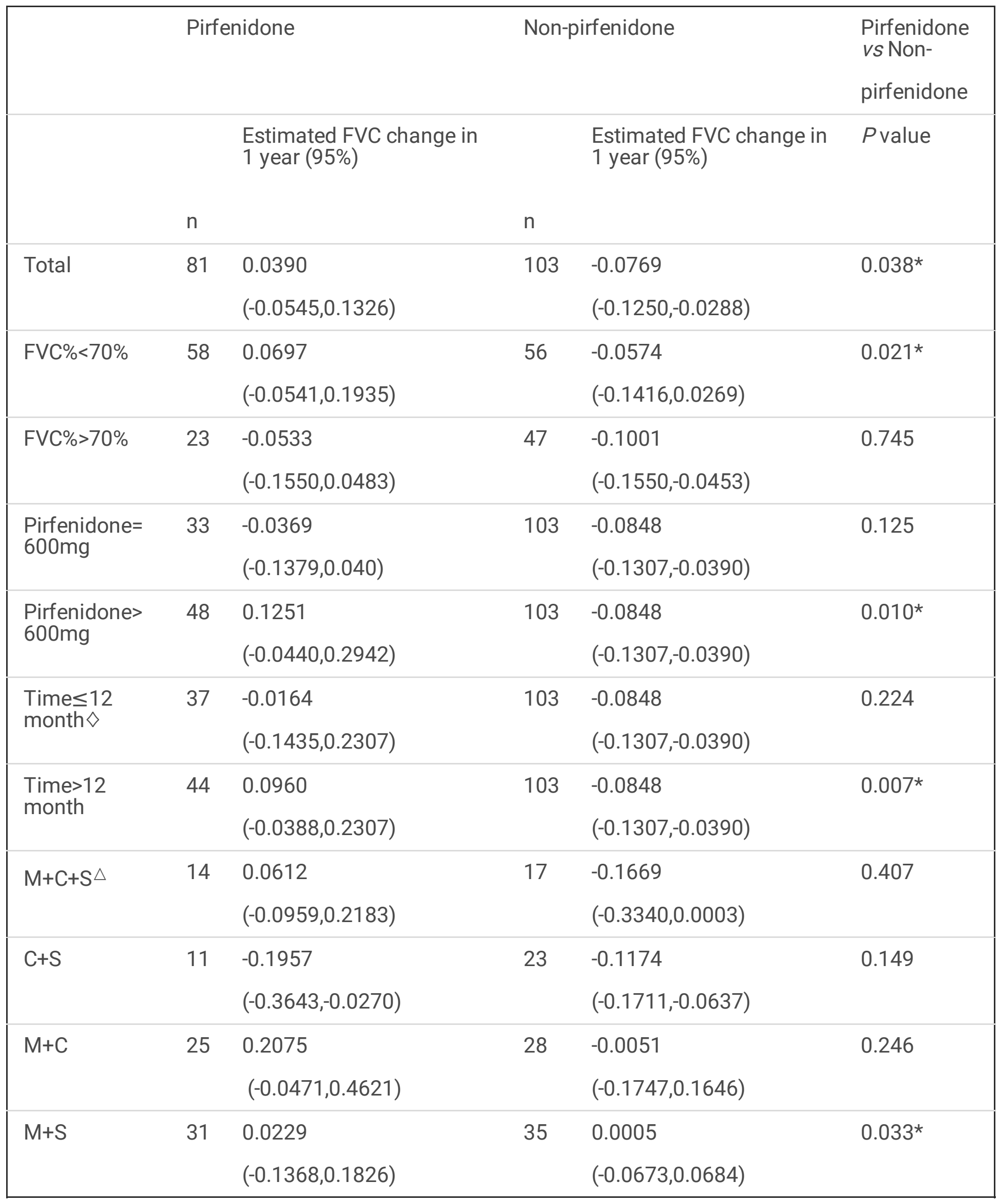

FVC\%-forced vital capacity\% predicted. \#Adjusted for age, sex, baseline forced vital capacity\% predicted and baseline carbon monoxide diffusing capacity\% predicted. $\diamond$ Grouped by the time of pirfenidone 
therapy. $\triangle$ Grouped according to the diagnostic domain. M-morphological domain, C-clinical domain, Sserological domain. * $P<0.05$

\section{Figures}

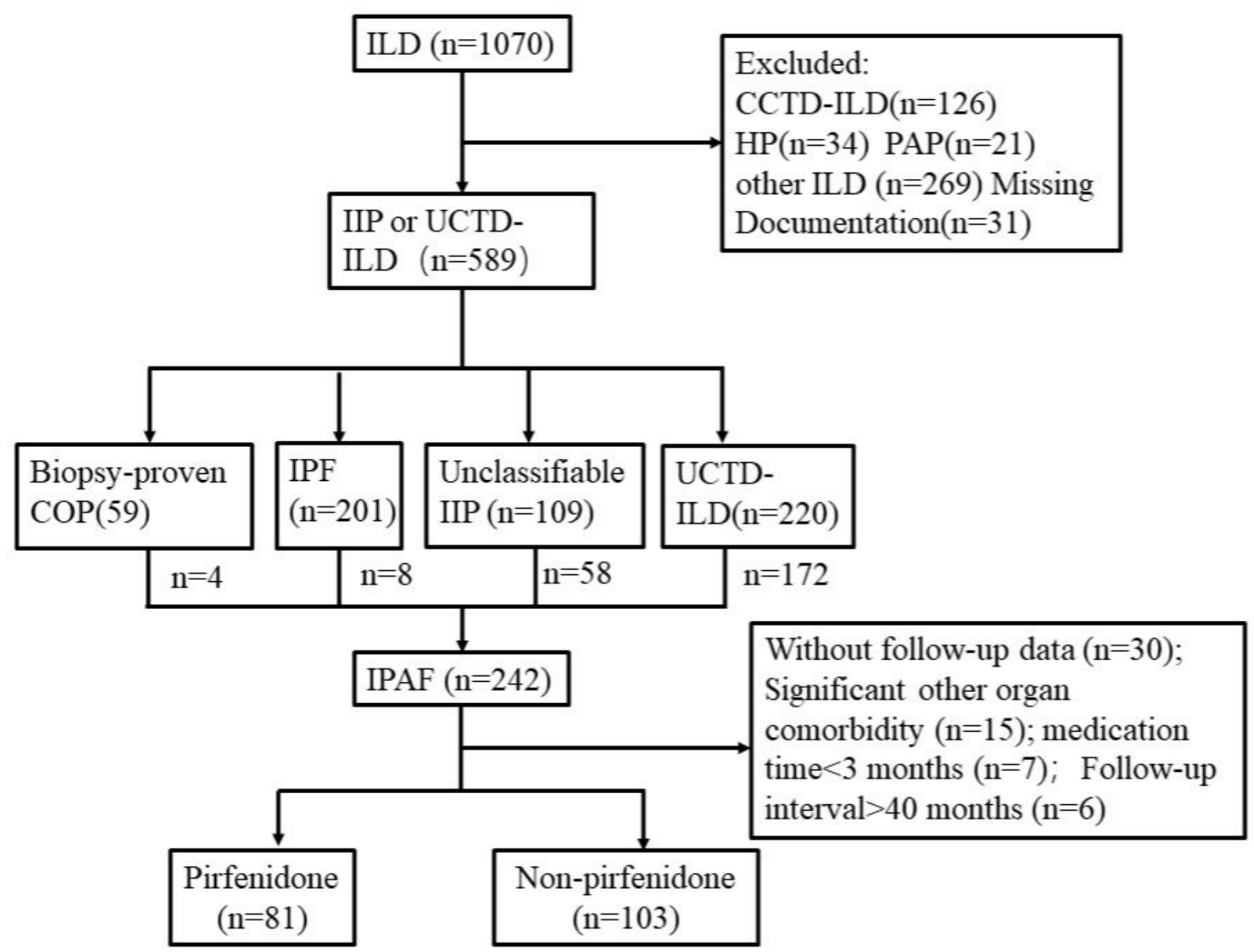

\section{Figure 1}

Flowchart of patients' selection process. Of 1070 patients diagnosed with ILD, 184 patients with IPAF (81 received pirfenidone therapy, while 103 didn't receive) were enrolled in this study. CCTD-ILD= Confirmed connective tissue disease-associated ILD; $C O P=$ cryptogenic organic pneumonia $\triangle \mathrm{HP}=$ hypersensitivity pneumonitis; IIP= idiopathic interstitial pneumonia; ILD= Interstitial lung disease; IPAF=Interstitial pneumonia with autoimmune features; IPF= idiopathic pulmonary fibrosis; $\mathrm{PAP}=$ pulmonary alveolar proteinosis; UCTD-ILD = undifferentiated connective tissue disease-associated ILD. 


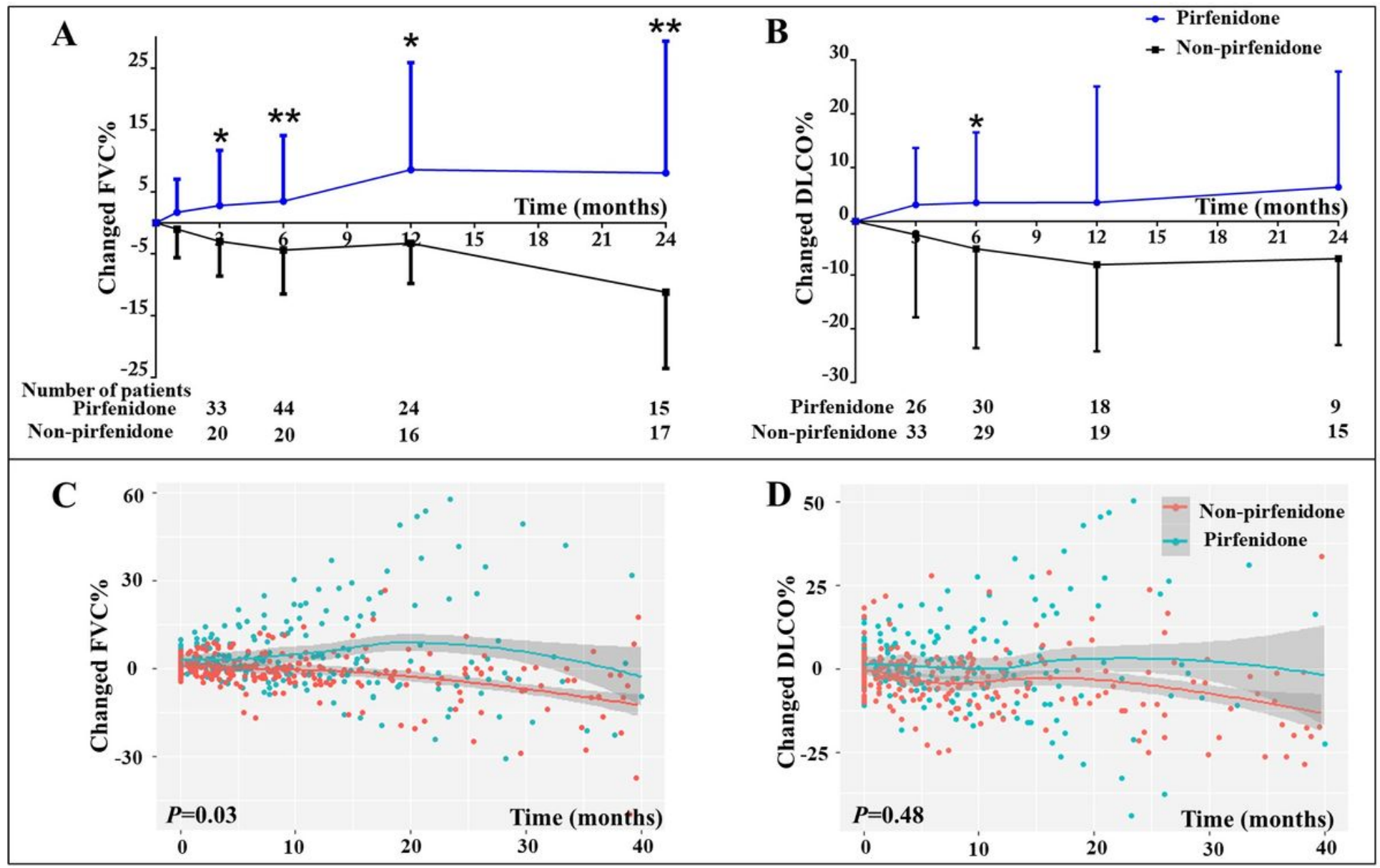

Figure 2

Changes of FVC\% and DLCO\% for two groups of IPAF patients. A\&B. Changes of FVC\% (A) and DLCO\% (B) in the corresponding time point for two groups of IPAF patients. C\&D. Adjusted changes in FVC\% (C) and DLCO\% (D) in the two groups of patients. The adjustment was performed by mix-effect model for gender, age, UIP pattern, baseline FVC\% and DLCO\%. 

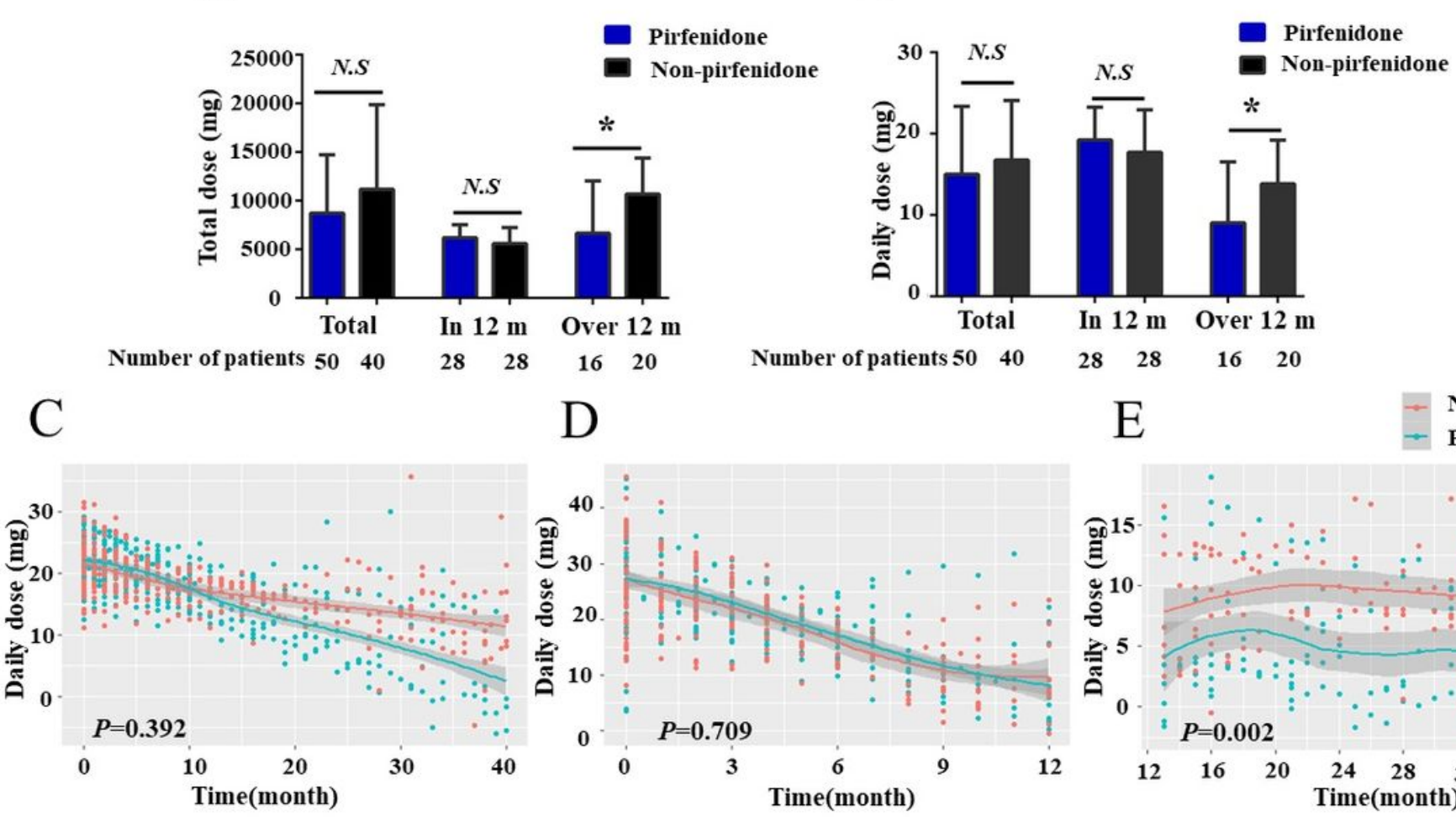

Non-pirfenidone Pirfenidone
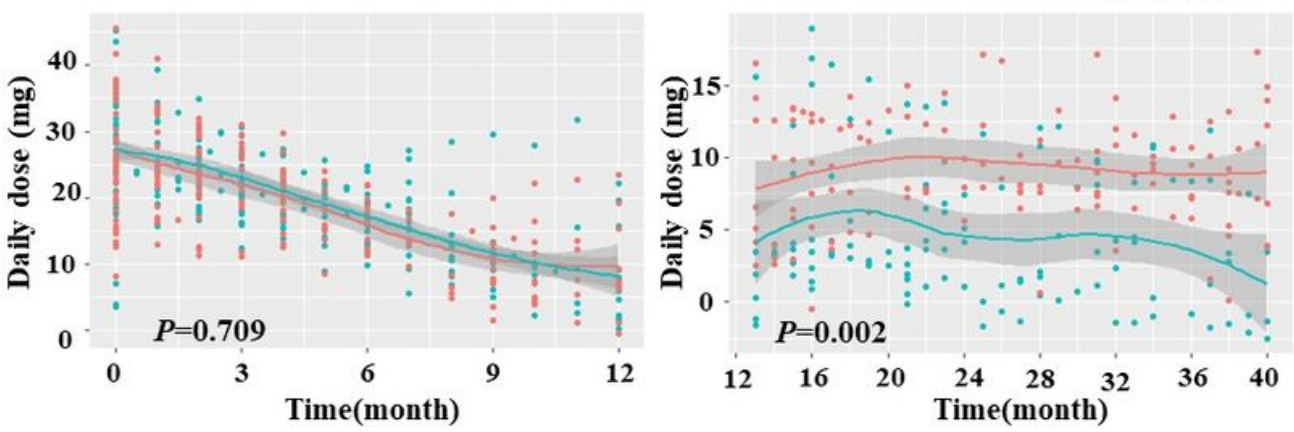

\section{Figure 3}

Prednisone dose over time for IPAF patients treated with or without pirfenidone A\&B. Total dose $(A)$ and average daily dose(B) of prednisone in the two groups of patients. C\&D\&E. The adjusted prednisone doses through overall observation time (C), in 12 months (D), and during month 12-40 (E). The adjustment was performed by mix-effect model for sex, age, UIP pattern, baseline FVC\%, and baseline DLCO\%.

A

\section{Side effect of pirfenidone}

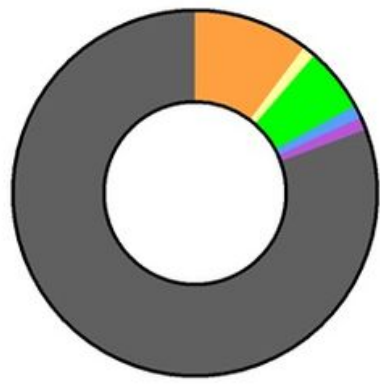

Total $=\mathbf{8 8}$
B

\section{Side effect with different dosages}
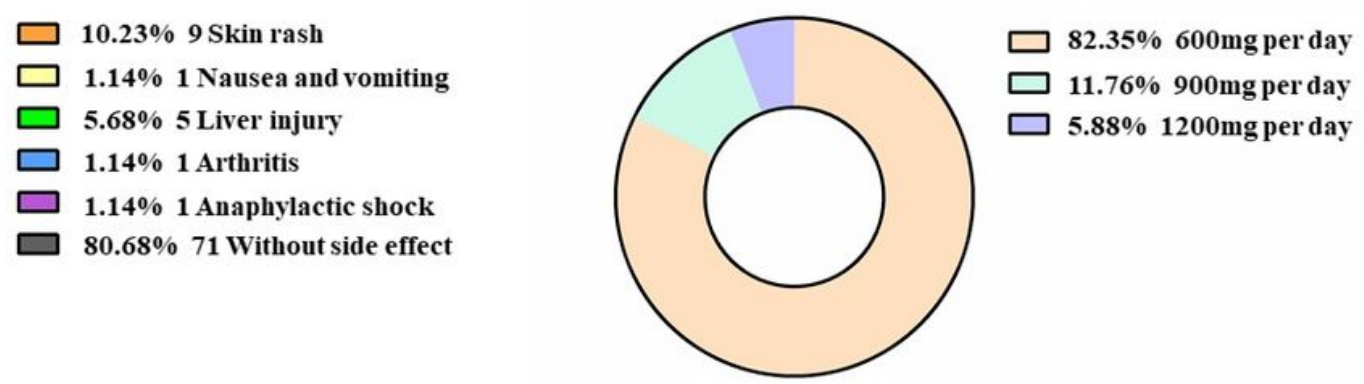

Total $=17$

\section{Figure 4}

Side effects of pirfenidone. A. 17 (19.32\%) patients in the pirfenidone group suffered from side effects, and 7 (7.95\%) patients stopped the pirfenidone therapy due to side effects. B. Side effects occurred in 14 
patients $(82.35 \%)$ with initial dosage (600 mg/day). 3 patients experienced side effects, while increasing pirfenidone dose.

\section{Supplementary Files}

This is a list of supplementary files associated with this preprint. Click to download.

- supplementary.docx 